\title{
Thermal Stability of High Density Polyethylene-Clay Nanocomposites Produced by in situ Solvent Polymerization
}

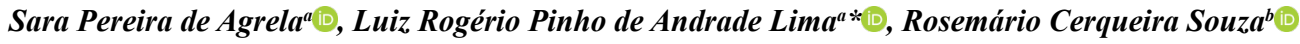 \\ ${ }^{a}$ Departamento de Ciência e Tecnologia dos Materiais, Escola Politécnica, Universidade Federal da Bahia \\ (UFBA), Rua Aristides Novis, 2, 40210-630, Salvador, BA, Brasil \\ ${ }^{b}$ Departamento de Química Analitica, Instituto de Química, Universidade Federal da Bahia (UFBA), \\ Rua Barão de Jeremoabo, 147, Campus de Ondina, 40.170-115, Salvador, BA, Brasil
}

Received: February 4, 2019; Revised: July 12, 2019; Accepted: December 4, 2019

\begin{abstract}
High density polyethylene and high density polyethylene-clay nanocomposites were produced using direct solvent polymerization and a Ziegler catalyst system $\left(\mathrm{TiCl}_{4}\right.$ and triethylaluminum in hexane). The produced polymer has a high average molecular weight and a multimodal molecular weight distribution composed of four distributions including a very high molecular weight component. The laboratory polymer has a thermal stability in inert atmosphere similar to the commercial high density polyethylene produced by Braskem. In oxidant atmosphere the produced polymer presents three thermal oxidation events above $400^{\circ} \mathrm{C}$ due to the combustion of low, medium and high molecular weight molecules. The thermal oxidation of the nanocomposites is shifted and reduced for high temperatures indicating an improvement in the thermal stability of the polymeric matrix due to the clay barrier effect for gases and volatile compounds.
\end{abstract}

Keywords: Polyethylene, Nanocomposite, Thermal degradation, Clay, In situ polymerization.

\section{Introduction}

Polymer-clay nanocomposites have received considerable attention in recent years due to their excellent mechanical and barrier properties. Polyolefines-clay nanocomposites are a very promising material, but the non-polar characteristic of these polymers makes the production of nanocomposites a challenging task ${ }^{1,2}$. Nowadays melt and solution intercalation are the most popular methods for nanocomposite production using a polymeric matrix that contains polar groups $s^{3,4,5}$. However, for a polyolefin matrix the in situ polymerization is the most effective method in clay exfoliation and in the production of nanocomposites ${ }^{1}$. In this study the production and the thermal stability of high density polyethylene produced using the conventional Ziegler-Natta catalyst system is addressed.

Several studies discuss the thermal stability of polymers in nanocomposites. The thermal degradation of polyethyleneclay nanocomposites produced by melt processing improves the stability and reduces inflammability due to the barrier effect and the charring process ${ }^{1,6}$. The thermal stability of high density polyethylene-clay nanocomposites produced by in situ polymerization has received less attention and only a few papers discuss this topic.

Jin et al. ${ }^{7}$ produced polyethylene nanocomposites by in situ polymerization using (i) sodium and (ii) organophilically modified montmorillonites intercalated with $\mathrm{TiCl}_{4}$ and activated by triethylaluminum (TEAL). The results indicated an average molecular weight of 102800 and 204600 and cristallinity of 37 and $34 \%$, respectively. The silicate layers were well dispersed in the polymer matrix.
Ramazani et al. ${ }^{8}$ produced polyethylene nanocomposites by in situ polymerization using a modified montmorillonite. The clay was activated using triisobutylaluminum (TIBA) or TEAL and after $\mathrm{TiCl}_{4}$ and ethylene was used in the polymerization. They used 2 to $9 \%$ clay and the produced polymer had a melting temperature between 132 and $133^{\circ} \mathrm{C}$, crystallinity of 66 to $70 \%$, and exhibited thermal stability until $400^{\circ} \mathrm{C}$.

Nikkhah et al. ${ }^{9}$ investigated the properties of polyethylene/ clay nanocomposites using the in situ polymerization and bi-supported catalyst (bentonite clay and $\mathrm{MgCl}_{2} / \mathrm{TiCl}_{4}$ ). The results indicated that the crystallization temperatures of the nanocomposites were significantly higher than that of pure polyethylene. There was an improvement in the thermal stability of the polymers. The good dispersion and exfoliation of the clay during the polymerization were responsible for obtaining improvements in the reinforcing properties of the clay in the polymer matrix.

Abedi et al. ${ }^{10}$ produced polyethylene/clay nanocomposites via in situ polymerization using $\mathrm{TiCl}_{4}$, TEAL and organometallic modifier butyloctylmagnesium (BOM) as the catalyst. The clay silicate layers were completely exfoliated in the polymer matrix. The thermal properties of the nanocomposites produced indicated the improved thermal stability of the nanocomposites when compared with pure polyethylene.

The purpose of this work is to produce a high density polyethylene and high density polyethylene-clay nanocomposite using direct solvent polymerization with a Ziegler type catalyst system $^{11}$, without catalyst support, and to characterize the polymers obtained and their thermal stability. 


\section{Experimental Procedure}

\subsection{Materials}

The materials used in the present study includes a reference material which was a commercial high density polyethylene produced by Braskem PE2 using the slurry-Mitsubishi process, a Ziegler-Natta catalyst (diethylaluminum chlorid, DEAC), co-catalysts (ethylaluminium sesquichloride, EASC and triethylaluminum, TEAL) and hexane as the solvent. This process uses controlled operating conditions and: i) parallel reactors for the production of the polymer with bimodal molecular weight distribution and ii) reactors in series, for the production of polymers with a monomodal molecular weight distribution. In the present case the sample BS002W is a bimodal resin and the sample JVU060 is a monomodal resin.

For the production of the polymer and nanocomposites the reactants used were: ethylene (99,99\%, White Martins SA), solution of $\mathrm{TiCl}_{4}(1 \mathrm{~mol} / \mathrm{L}$ in methylene chloride, Sigma-Aldrich), solution of triethylaluminum (93\% Sigma-Aldrich), ethanol (99.99\%, Merck), hexane (99.99\%, Merck), metallic sodium (99.99\%, Merck), benzophenone (99.99\%, Merck), nitrogen (99.99\%, White Martins SA) and Nanomer ${ }^{\circledR}$ I.44 P (Sigma Aldrich), which is $35-45 \mathrm{wt} \%$ dimethyl dialkyl (C14-C18) amine montmorillonite clay with particle size finer than $20 \mu \mathrm{m}$.

\subsection{Production of polymers and nanocomposites}

The ethylene polymerization reactions were carried out in a $250 \mathrm{~mL}$ stainless steel bench top Parr Instruments stirred reactor (Series 4560), which had a gas inlet, stirring speed adjustment and temperature control. Initially the reactor was purged with $\mathrm{N}_{2}$ and $150 \mathrm{~mL}$ of dry hexane was added, then a hexane solution of $\mathrm{TiCl}_{4}\left(0.3\right.$ or $0.8 \mathrm{~mL}$ of $\mathrm{TiCl}_{4}$ in $10 \mathrm{~mL}$ of hexane) and a hexane solution of TEAL was added (0.9, 1.8 or $2.6 \mathrm{~mL}$ of TEAL in $10 \mathrm{~mL}$ of hexane) as catalyst and cocatalyst. The molar ratio (Al/Ti) was 20 or 29 . The injection of ethylene in this system initiated the polymerization that was discontinued after 60 or 90 minutes by reactor depressurizing and the addition of $10 \mathrm{~mL}$ of ethanol. The polymerizations were carried out at a temperature between 77 or $85^{\circ} \mathrm{C}$ with constant stirring at $190 \mathrm{rpm}$ and pressure between 2.1 and 2.7 bar.
The experimental conditions for polymer synthesis, selected according with previous work by Jin et al. ${ }^{7}$ and Haag and Silva ${ }^{11}$, are summarized in Table 1. After the reaction ended, the reactor content was filtered at vacuum and washed using ethanol and then distilled water to remove the hexane and catalytic residues. After this, the polymer was dried at $80^{\circ} \mathrm{C}$ for 24 hours.

For the synthesis of the nanocomposites three different addition strategies were used:

i) Initially the nanoclay (Nanomer $(\mathrm{I} 44 \mathrm{P})$ was added to the reactor, then it was purged with $\mathrm{N}_{2}$ and $150 \mathrm{~mL}$ of dry hexane was added. It was impregnated by $\mathrm{TiCl}_{4}$ (a solution of $0.6 \mathrm{~mL}$ of $\mathrm{TiCl}_{4}$ in $10 \mathrm{~mL}$ of hexane) for 60 minutes, then a solution TEAL (1.8 $\mathrm{mL}$ in $10 \mathrm{~mL}$ of hexane) was added, the following steps are the same as for the production of the polymers described above.

ii) Initially the nanoclay was added to the reactor, then it was purged with $\mathrm{N}_{2}$ and $150 \mathrm{~mL}$ of dry hexane was added, the following steps are the same as for the production of the polymers described above.

iii) Initially the nanoclay was added to the reactor and $150 \mathrm{~mL}$ of dry hexane was added. The Lab_Line Ultratip Labsonic System was used to enhance the clay dispersion on the hexane. Then it was purged with $\mathrm{N}_{2}$ and the following steps are the same as for the production of the polymers described above.

The molar ratio $(\mathrm{Al} / \mathrm{Ti})$ used in the polymerizations was 29. The experimental conditions for the synthesis of composites and nanocomposites are summarized in Table 2 .

\subsection{Polymer and nanocomposite characterizations}

The catalyst activity or efficiency on the polymerization $\left(r_{p}\right)$ was estimated taking into account the mass of polymer produced $\left(\mathrm{m}_{\mathrm{PE}}\right)$, the reaction time $\left(\mathrm{t}_{\mathrm{p}}\right)$ and the amount of titanium used in the reaction $\left(\mathrm{m}_{\mathrm{Ti}}\right)$ :

$$
r_{p}=\frac{m_{P E}}{m_{T i} t_{P}}=\frac{m_{P E}}{V_{T i} C_{T i} t_{P}}\left(k g_{P E} / m_{T i} h\right)
$$

Table 1. Experimental conditions used in the polymers production

\begin{tabular}{ccccccc}
\hline Test & $\begin{array}{c}\text { Temperature } \\
\left({ }^{\mathbf{C}} \mathbf{C}\right)\end{array}$ & $\begin{array}{c}\text { Reaction Time } \\
(\mathbf{m i n})\end{array}$ & $\begin{array}{c}\text { Stirring speed } \\
(\mathbf{r p m})\end{array}$ & $\begin{array}{c}\text { Volume of } \\
\left.\mathbf{T i C l}_{\mathbf{4}} \mathbf{( m L}\right)\end{array}$ & $\begin{array}{c}\text { Volume of } \\
\mathbf{T E A L}(\mathbf{m L})\end{array}$ & $\begin{array}{c}\mathbf{A l} / \mathbf{T i} \\
\left(\mathbf{m o l}_{\mathbf{A l}} \mathbf{\mathbf { m } _ { \mathbf { m } }}\right.\end{array}$ \\
\hline HDPE 1 & 85 & 60 & 190 & 0.8 & 2.6 & 29 \\
HDPE 2 & 50 & 90 & 190 & 0.3 & 0.9 & 20 \\
HDPE 3 & 85 & 90 & 190 & 0.8 & 2.6 & 29 \\
\hline
\end{tabular}

Table 2. Experimental conditions used in the nanocomposites production

\begin{tabular}{cccccccc}
\hline Test & $\begin{array}{c}\text { Temperature } \\
\left({ }^{\circ} \mathbf{C}\right)\end{array}$ & $\begin{array}{c}\text { Reaction } \\
\text { time }(\mathbf{m i n})\end{array}$ & $\begin{array}{c}\text { Stirring } \\
\text { speed }(\mathbf{r p m})\end{array}$ & $\begin{array}{c}\text { Volume of TiCl } \\
(\mathbf{m L})\end{array}$ & $\begin{array}{c}\text { Volume of } \\
\text { TEAL }(\mathbf{m L})\end{array}$ & $\begin{array}{c}\text { Nanoclay weight } \\
(\mathbf{g})\end{array}$ & $\begin{array}{c}\text { Al/Ti } \\
(\mathbf{m o l} / \mathbf{A l} / \mathbf{m o l T i})\end{array}$ \\
\hline $\mathrm{N} 1, \mathrm{~N} 2$ and N3 & 85 & 90 & 190 & 0.6 & 1.8 & 0.2 & 29 \\
\hline
\end{tabular}


The average molecular weight is related to the viscosity of the polymer. In the present study it was estimated using the Braskem method, which is based on the ASTM D-4020 and ISO 1628-3 methods ${ }^{12,13}$. A Ubbelohd viscosimeter n.1 was used to measure the polymer solution viscosity as a function of the polymer concentration (between 0.01 and $0.02 \mathrm{~g} / \mathrm{dL}$ in decahydronaphthalene at $135^{\circ} \mathrm{C}$ ). The specific viscosity $\left(\eta_{\mathrm{sp}}\right)$ is defined as the ratio of the difference between the viscosities of the solution $(\eta)$ and solvent $\left(\eta_{\mathrm{s}}\right)$ and the viscosity of the solvent:

$$
\eta_{s p}=\frac{\left(\eta-\eta_{s}\right)}{\eta_{s}}
$$

The relative viscosity $\left(\eta_{\text {rel }}\right)$ is defined as the ratio of the viscosity of the solution to the viscosity of the solvent:

$$
\eta_{r e l}=\frac{\eta}{\eta_{s}}
$$

The intrinsic viscosity ([ๆ]) for high density polyethylene is estimated at very low solution concentration using a single concentration and solution viscosity data (C and $\eta)$ and the ASTM correlation:

$$
[\eta]=\frac{\left(2 \eta_{s p}-2 \ln \left(\eta_{r e l}\right)\right)^{1 / 2}}{C}
$$

The viscosimetric molecular weight of a polymer is close to the average molecular weight and is estimated using the Margolies equation:

$$
M v=5.37 \times 10^{4}[\eta]^{1.49}
$$

The melting temperatures of the polymers were obtained by differential scanning calorimetry (DSC) using the Shimadzu DSC-50, with nitrogen flow at $30 \mathrm{~mL} / \mathrm{min}$ and a heating rate of $10^{\circ} \mathrm{C} / \mathrm{min}$ in a temperature range of 30 to $600^{\circ} \mathrm{C}$.

The polymer solid content was evaluated after the thermal degradation of the samples at 600 and $900^{\circ} \mathrm{C}$ in an oxidant atmosphere in a laboratory bench Quimis oven. The solid content was characterized using a scanning electron microscope and X-ray spectra (EDS) using the JEOL JSM 6610LV.

The polymer crystallinity $(\chi c)$ was estimated from the melting enthalpy for the samples $\left(\Delta H_{\text {Sample }}^{o}\right.$ estimated as the area under the endothermic peak/heating rate) using as reference enthalpy for $100 \%$ crystalline high molecular weight polyethylene $\left(\Delta H_{f}^{o}=293 \mathrm{~J} / \mathrm{g}\right)$ as follows:

$$
\chi_{c}=\left(\frac{\Delta H_{\text {Sample }}^{o}}{\Delta H_{f}^{o}}\right) \times 100
$$

The thermal stability of the polymers was evaluated using thermogravimetric and differential thermal analysis (TGA/ DTA), performed using the Shimadzu DTG-60H. In this case samples of about $4.0 \mathrm{mg}$ were placed in the platinum sample holder and the runs were performed in the range of $25-600^{\circ} \mathrm{C}$, with a heating rate of $10^{\circ} \mathrm{C} / \mathrm{min}$ under $50 \mathrm{~mL} /$ min of nitrogen atmosphere.
The kinetics for most of the cases of polymer thermal degradation are described as a single-step process by the rate equation:

$$
\frac{d \alpha}{d t}=A \exp \left(\frac{-E_{a}}{R T}\right) f(\alpha)
$$

where $\alpha$ is the conversion $\left(\alpha=\left(m_{i}-m_{T}\right) /\left(m_{i}-m_{f}\right)\right.$, where $\mathrm{m}_{\mathrm{T}}$ is the mass at temperature $T, m_{i}$ is the initial mass and $m_{f}$ is the final mass), $\mathrm{E}_{\mathrm{a}}$ is the Arrhenius activation energy, $\mathrm{A}$ is the preexponential factor, $\mathrm{R}$ is the universal gas constant, $\mathrm{T}$ the temperature, and $f(\alpha)$ is the reaction mathematical model. The conversion can be estimated by thermogravimetric analysis (TGA). In the present case, the apparent activation energy for the polymer degradation was evaluated using TGA at different heating rates using Shimadzu TGA-50, under $50 \mathrm{~mL} / \mathrm{min}$ of nitrogen and heating rates of $5,10,15$ and $20^{\circ} \mathrm{C} / \mathrm{min}$. The activation energy was estimated using the Ozawa-Flynn-Wall method for conversion ranging from 20 to $90 \%$, using the Arrhenius plotting of the heating rate $(\beta)$ and the temperature at the defined conversion $\left(\mathrm{T}_{\mathrm{i}}\right)$. The slope of the plot $\ln \beta$ versus $1 / \mathrm{T}_{\mathrm{i}}$ is $\mathrm{E}_{\mathrm{a}} / \mathrm{R}^{14}$.

The molecular weight distribution was measured using gel permeation liquid chromatography (GPC) according to ASTM D $6474^{15}$. The samples of polymer were dissolved in a solvent then injected onto a high temperature chromatographic column that had a solid packed substrate. This process separates the molecules of the polymer according to their size in the solution. As the separated molecules permeate from the column they are detected. The retention times are converted through molecular weights and the distributions are determined from the molecular weight concentration data. This method uses a polystyrene standard for calibration. In the present case, the equipment used was the GPC IR Polymer Char (which has three detectors: infrafred, viscometer and light scattering) using the infrared detector. The equipment uses four TOSOH GPC TSKgel ${ }^{\circledR}$ speakers. The solvent used was 1,2,4-trichlorobenzene (TCB), the solvent flow rate was $1 \mathrm{~mL} / \mathrm{min}$ and the temperature $140^{\circ} \mathrm{C}$. The result of the GPC is a plot of the weight fraction as a function of the molecular weight. This plot can have several peaks on a multimodal distribution, so a peak decovolution, which is a well known mathematical procedure, is mandatory to identify the contribution of each distribution on the experimental result. In the present case the decovolution of the molecular weight distributions were performed using OriginLab software version 7.0 taking into account the presence of two to four peaks in the molecular weight distribution.

For the nanocomposites, the crystallinity of the polymers was evaluated using X-ray diffraction performed with the Shimadzu XRD-6000 diffractometer. The thermal stability was evaluated using thermogravimetric and differential thermal analysis (TGA/DTA), performed using the Shimadzu DTG-60H with a heating rate of $10^{\circ} \mathrm{C} / \mathrm{min}$ under $50 \mathrm{~mL} /$ min of synthetic air. 


\section{Results and Discussion}

\subsection{Characterization of the polymers}

The catalyst activity of the polymerization reaction is relatively low and significantly dependent on the $\mathrm{Al} / \mathrm{Ti}$ molar ratio as shown at Tables 1 and 3 . The intrinsic viscosity for the polyethylene produced was $8.2 \mathrm{dL} / \mathrm{g}$ and the average molecular weight was $1.23 \times 10^{6} \mathrm{~g} / \mathrm{mol}$. This indicates that the polymer produced has a large molecular weight and is classified as high density polyethylene.

Figure 1a shows the DSC results for polyethylene obtained in laboratory (HDPE 1,2 and 3) and samples of the commercial high molecular weight polyethylene (JV060U and BS002W). The commercial samples present a melting temperature of 131 and $133^{\circ} \mathrm{C}$, respectively, and the laboratory samples 133 and $134^{\circ} \mathrm{C}$, which confirm the production of high molecular weight polyethylene.

Figure $1 \mathrm{~b}$ shows the termogravimetric analysis data for the samples in an inert atmosphere. It can be seen that the samples degrade in a single step and the JV060U sample has higher thermal stability. The JV060U and BS002W polymers start thermal degradation at about 400 and $350^{\circ} \mathrm{C}$ and reach zero mass at about $500^{\circ} \mathrm{C}$. The laboratory sample starts degradation at about $350^{\circ} \mathrm{C}$ and reaches zero mass at about $500^{\circ} \mathrm{C}$, which is the same behavior of BS002W.
The inert atmosphere differential thermal analysis (DTA) curves for the commercially produced and laboratory samples are shown in Figure 1c. Samples JV060U and BS002W showed a first endothermic event which is related to the melting temperatures at 133 and $136^{\circ} \mathrm{C}$ and a second and third endothermic events at 477 and $442^{\circ} \mathrm{C}$ and an exothermic event at high temperature. These events are related to the cross chain thermal decomposition including the elimination of volatile molecules of low and medium molecular weight. The laboratory sample has a melting temperature of $134^{\circ} \mathrm{C}$ and has two decomposition temperatures at 443 and $477^{\circ} \mathrm{C}$, similar to those of the commercial sample BS002W.

Tables 3 and 4 shows the solid residual content of the laboratory and commercial polymer samples after the thermal degradation at $600^{\circ} \mathrm{C}$ in an oxidant atmosphere. It can be seen that the laboratory polymer samples have about $2 \%$ solid residues while the commercial samples have about $0.1 \%$. Figure 2 a shows the SEM images in the secondary electron of the laboratory polymer. Figure $2 \mathrm{~b}$ shows the solid residue after the laboratory polymer calcinations at $900^{\circ} \mathrm{C}$. It shows that this solid was sinterized and the composition is mainly aluminum oxide with traces of titanium oxide, which is the residue of the co-catalyst and catalyst used in the polymerization process.

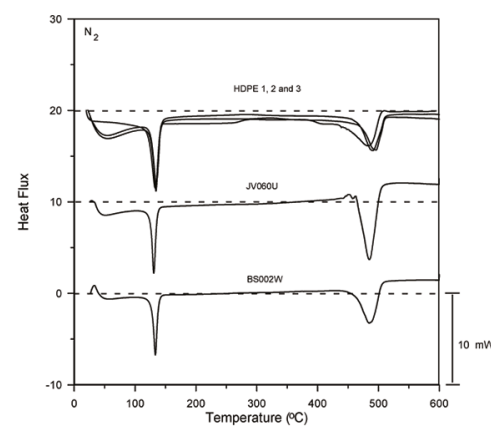

a

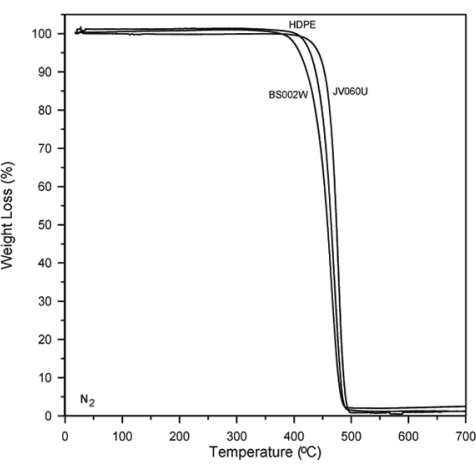

b

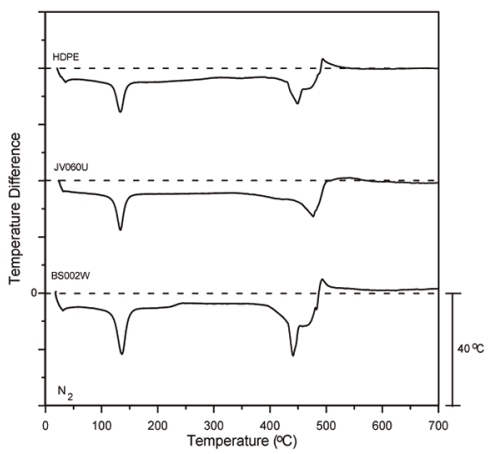

$\mathrm{C}$

Figure 1. Thermal degradation in an inert atmosphere of commercial (BS002W and JV060U) and laboratory (HDPE) high density polyethylene: a) Differential scanning calorimetry, b) Thermo gravimetric analysis, c) Differential thermal analysis.

Table 3. In situ polymerization results and properties of polymers produced

\begin{tabular}{cccccc}
\hline Sample & $\begin{array}{c}\text { Catalyst efficiency } \\
\left(\mathrm{kg}_{\mathrm{PE}} / \mathrm{mol}_{\mathrm{Ti}} \mathrm{h}\right)\end{array}$ & $\begin{array}{c}\text { Solid weight fraction after } \\
\text { thermal oxidation at } 600^{\circ} \mathrm{C}(\%)\end{array}$ & $\begin{array}{c}\text { Melting Temperature, } \\
\mathrm{T}_{\mathrm{m}}\left({ }^{\circ} \mathrm{C}\right)\end{array}$ & $\begin{array}{c}\text { Enthalpy of fusion, } \\
\Delta \mathrm{H}_{\mathrm{m}}(\mathrm{J} / \mathrm{g})\end{array}$ & $\begin{array}{c}\text { Degree of crystallinity, } \\
\chi_{c}(\%)\end{array}$ \\
\hline HDPE 1 & 2.5 & 1.9 & 134.4 & 163.9 & 52 \\
HDPE 2 & 1.8 & 2.7 & 134.3 & 164.1 & 52 \\
HDPE 3 & 2.1 & - & 133.2 & - & - \\
\hline
\end{tabular}

Table 4. Properties of the commercial polymers

\begin{tabular}{lcccc}
\hline Sample & $\begin{array}{c}\text { Melting Temperature, } \\
\operatorname{Tm}\left({ }^{\circ} \mathrm{C}\right)\end{array}$ & $\begin{array}{c}\text { Solid weight fraction after thermal oxidation at } \\
600^{\circ} \mathrm{C}(\%)\end{array}$ & $\begin{array}{c}\text { Enthalpy of fusion, } \Delta \mathrm{H}_{\mathrm{m}} \\
(\mathrm{J} / \mathrm{g})\end{array}$ & $\begin{array}{c}\text { Degree of crystallinity, } \chi_{c} \\
(\%)\end{array}$ \\
\hline JV060U & 130.9 & 0.1 & 194.8 & 61 \\
BS002W & 133.4 & 0.1 & 167.6 & 53 \\
\hline
\end{tabular}


The DSC results (Figure 1a) also enable the evaluation of the degree of crystallization of the polymers. For the commercial samples, JV060U has a melting temperature of $131^{\circ} \mathrm{C}$ and heat of fusion $194.8 \mathrm{~J} / \mathrm{g}$ and BS002W has melting temperature of $133^{\circ} \mathrm{C}$ and heat of fusion $167.6 \mathrm{~J} / \mathrm{g}$. For the laboratory polymers the melting temperature is 133 and $134^{\circ} \mathrm{C}$, which correspond to the melting enthalpies of 163.9 and $164.1 \mathrm{~J} / \mathrm{g}$. The degree of crystallization of the laboratory and commercial polymers are presented in Tables 3 and 4 . The crystalline of the commercial polymers (JV060U and BS002W) was 61 and $53 \%$, and the crystalline of the laboratory polymer was $52 \%$, which is close to the value of one of the commercial samples.

Figure 3a shows the TGA curves for the thermal degradation of the laboratory polymers at an inert temperature for four different heating rates $\left(5,10,15\right.$ and $\left.20^{\circ} \mathrm{C} / \mathrm{min}\right)$. It was found that the thermal degradation occurs in a single step between 400 and $500^{\circ} \mathrm{C}$. The apparent activation energy for the laboratory polymers thermal degradation is shown in Figure $3 \mathrm{~b}$.
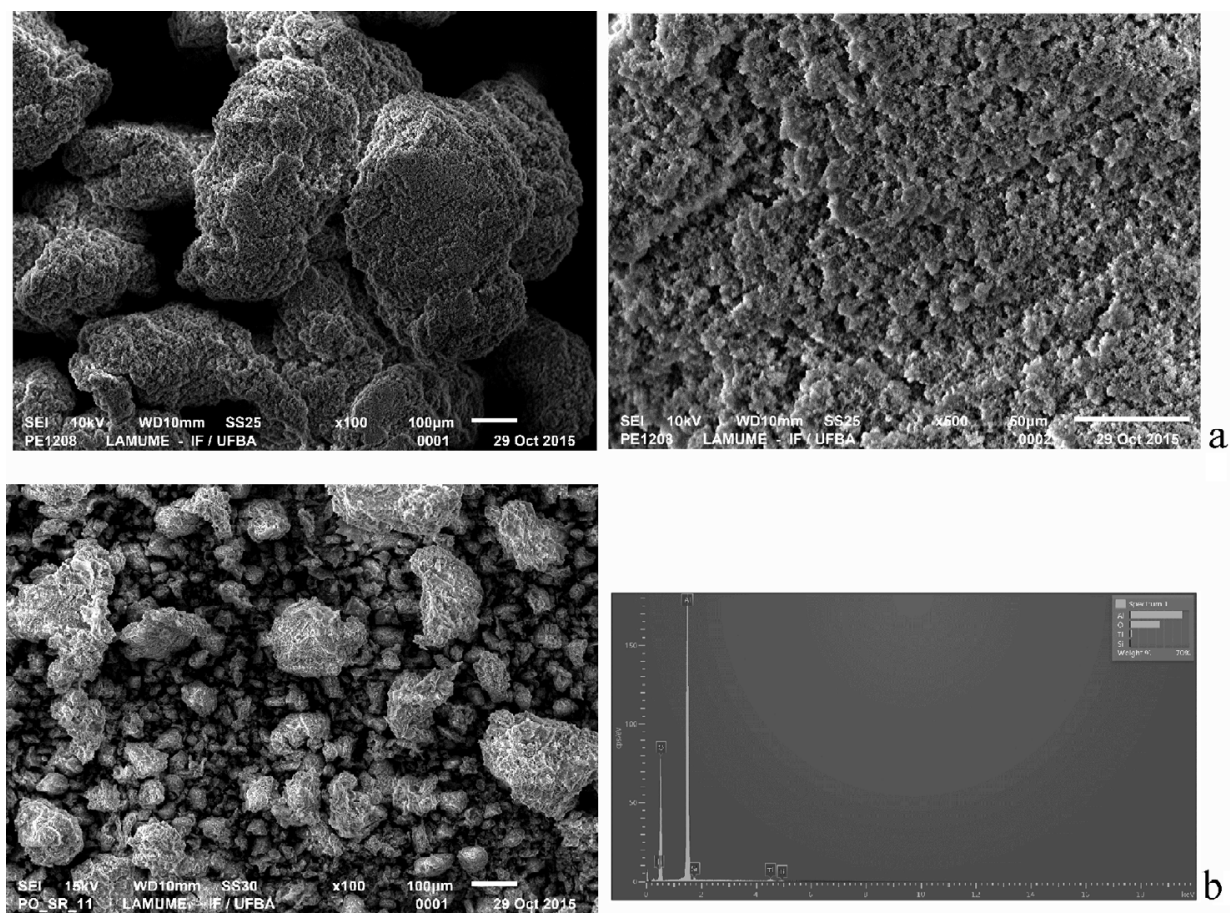

Figure 2. a) SEM image in secondary electron of laboratory polymer. b) SEM image in secondary electron and EDS spectra of the polymer solid residue after thermal oxidation at $900^{\circ} \mathrm{C}$.
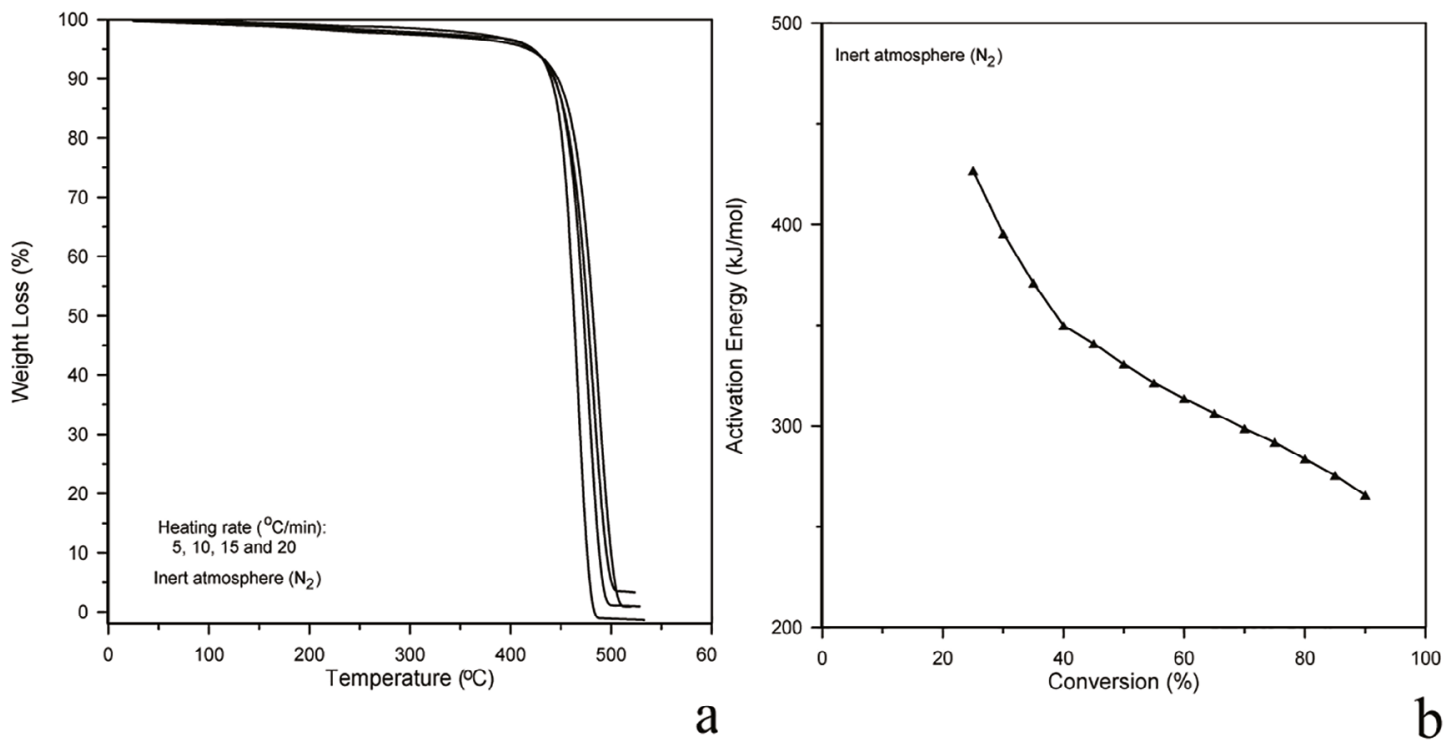

Figure 3. Thermal degradation kinetics on inert atmosphere of the laboratory (HDPE) high density polyethylene: a) Thermo gravimetric analysis for heating rate between 5 and $20^{\circ} \mathrm{C} / \mathrm{min}$, b) Apparent activation energy obtained by isoconversional analysis of TGA data. 
The activation energy is from 260 to $440 \mathrm{~kJ} / \mathrm{mol}$, values higher than those reported in the literature ${ }^{16,17}$, indicating that the molecular weight for the laboratory polymers is higher than conventional high density polyethylene.

The molecular weight distribution of the commercial and laboratory polyethylene samples estimated using GPC are shown at Figure 4. It can be observed that JV060U exhibits a narrow dispersion monomodal molar weight distribution, and BS002W presents a medium dispersion bimodal molar weight distribution, both distributions with a similar average value $(\log M=4.7)$. The laboratory polymers (HDPE 1,2 and 3) present a broad dispersion multimodal molar weight distribution with a high average value $(\log M=5.5)$.

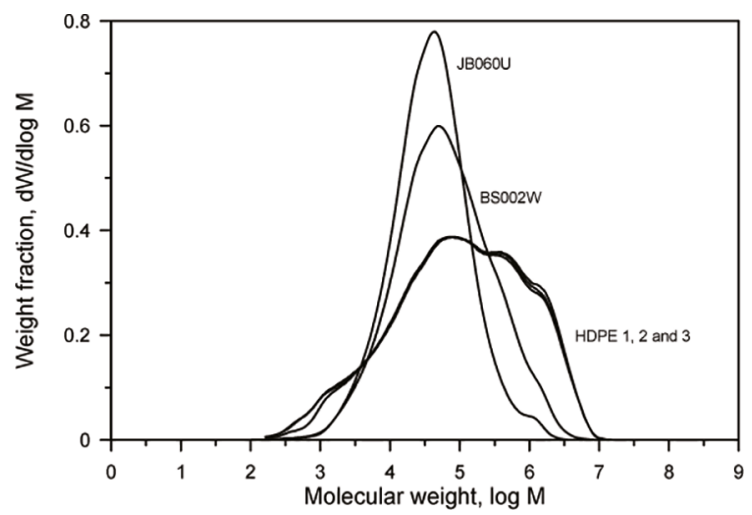

Figure 4. Molecular weight distribution of the commercial and laboratory polymers.

Figure 5a shows the deconvolution of the molecular weight distributions of sample JV060U. It has two peaks (at $\log \mathrm{M}=4.6$ and 6.0), but the second peak is very small indicating that this material is practically monomodal. Figure $5 \mathrm{~b}$ shows the deconvolution of the molecular weight distributions of sample BS002W. There are two peaks (at log $\mathrm{M}=4.7$ and 5.8) indicating that this material is bimodal. Figure $5 \mathrm{c}$ shows the deconvolution of the molecular weight distribution of a laboratory polymer (HDPE). Here there are 4 peaks (at $\log \mathrm{M}=3.3,4.8,5.8$ and 6.3) indicating a large molar weight and multimodal distribution. The predominant distributions are the second and fourth, which have average values (at $\log \mathrm{M}=4.8$ and 6.3).

Figure 6a shows the XRD pattern for the laboratory samples (HDPE 1, 2, and 3) and laboratory nanocomposites (HDPE + Nanoclay 1, 2, and 3). The presence of two characteristic crystalline peaks at $2 \theta=21.7^{\circ}$ and $2 \theta=24^{\circ}$ were observed, corresponding to the orthorhombic crystal structure of polyethylene, planes (110) and (200). A small peaks were observed for the nanocomposites at around $2 \theta=35^{\circ}$, which is probably due to the silicate. Under the large peaks of the polyethylene there is a halo from the amorphous fraction of the polymer. There is no visible difference between the crystalline/amorphous composition in the pure polymers and the polymers in the nanocomposites.
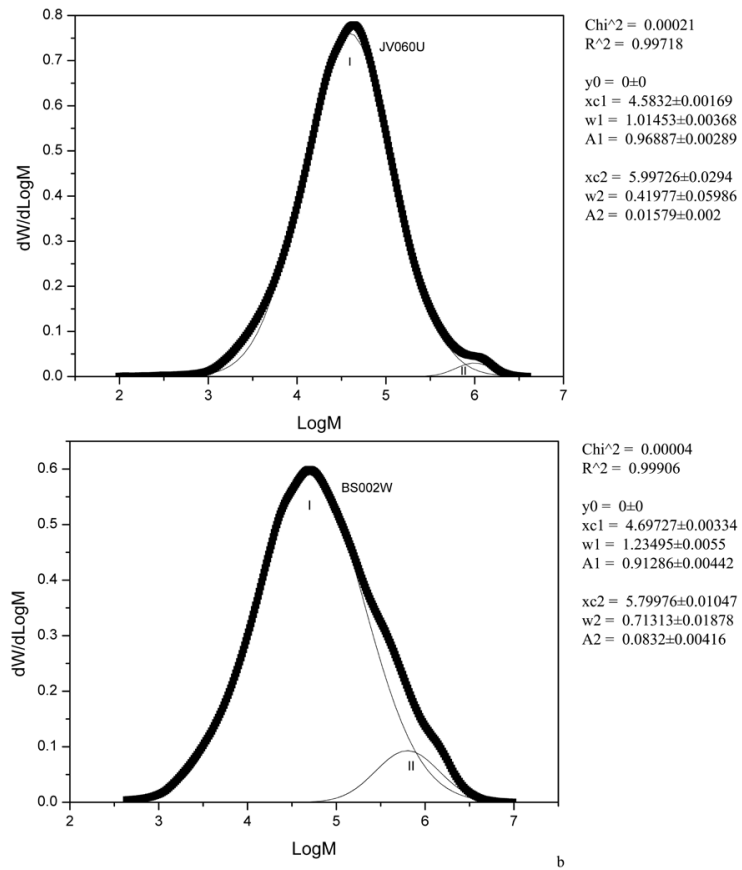

$\mathrm{Chi}^{2} 2=0.00004$ $\mathrm{R}^{\wedge} 2=0.99906$ $\mathrm{y} 0=0 \pm 0$ $\begin{aligned} \mathrm{xc} 1 & =4.69727 \pm 0.00334 \\ \mathrm{w} 1 & =1.23495+0.0055\end{aligned}$ $\mathrm{w} 1=1.23495 \pm 0.0055$
$\mathrm{~A} 1=0.91286 \pm 0.00442$ $\mathrm{xc} 2=5.79976 \pm 0.01047$ $\mathrm{w} 2=0.71313 \pm 0.01878$ $\mathrm{A} 2=0.0832 \pm 0.00416$

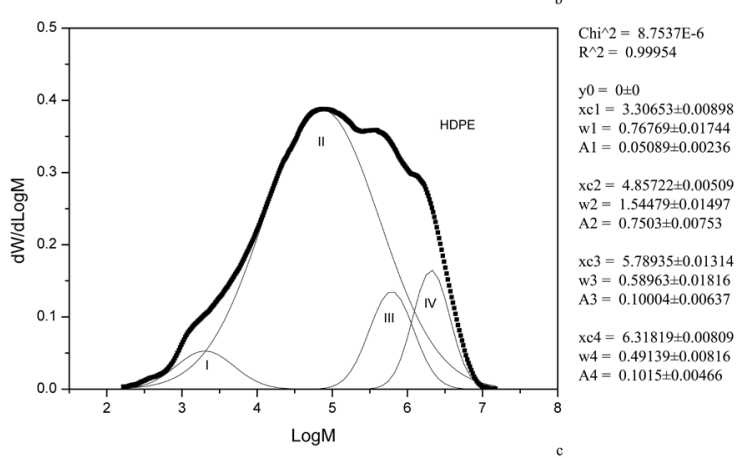

Figure 5. Decovolution of the molecular weight distribution: a) JV060U, b) BS002W, c) laboratory polymer.

Figure $6 \mathrm{~b}$ shows the XRD pattern for the nanoclay and the nanocomposites at low angles. The characteristic peak of the modified montmorilonite is not present at the nanocomposite samples, which indicates the exfoliation and homogenization of the nanoclay in the nanocomposites.

Figure 7a shows the thermogravimetric analysis in an oxidant atmosphere for the samples of laboratory polymer (HDPE 1 and 2) and one nanocomposite sample (HDPE + Nanoclay, N1). It can be seen that the polymers curves present several different regions (I, II and III) which indicate the thermal oxidation of low, medium and high molecular weight polymers. The nanocomposite curve presents a low temperature thermal oxidation behavior, but at higher temperatures there is a reduction in the thermal oxidation. The correspondent differential thermal analysis (DTA) for oxidant atmosphere is shown in Figure $7 \mathrm{~b}$. For the laboratory polymers, an endothermic event (the polymer melting) and several exothermic events (thermal oxidation) can be observed. The first exothermic event (at about $250^{\circ} \mathrm{C}$ ) corresponds to the oxidation of volatile compounds. 

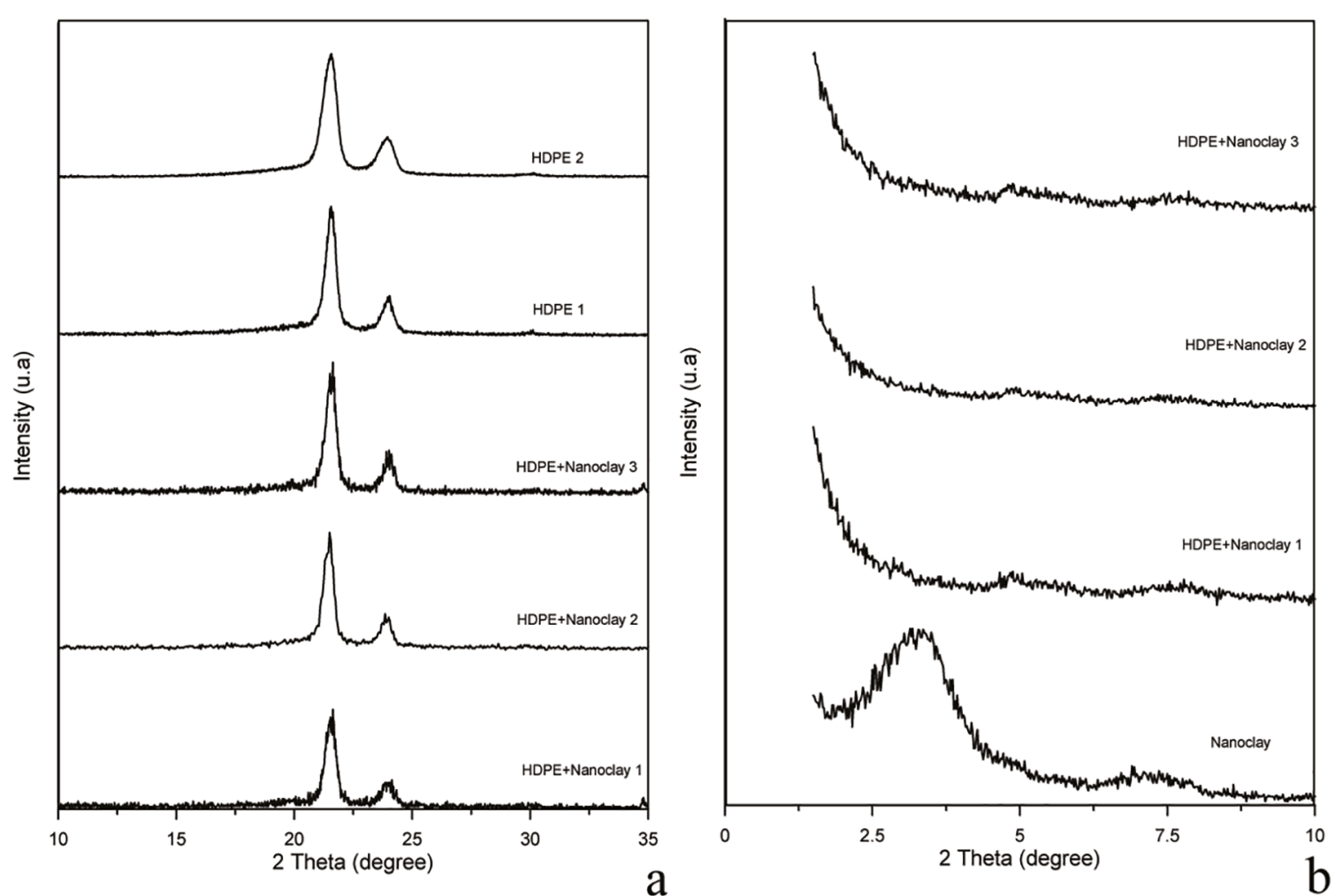

Figure 6. XRD patterns: a) High molecular weight polyethylene and nanocomposites. b) Low angle for the clay and nanocomposites.
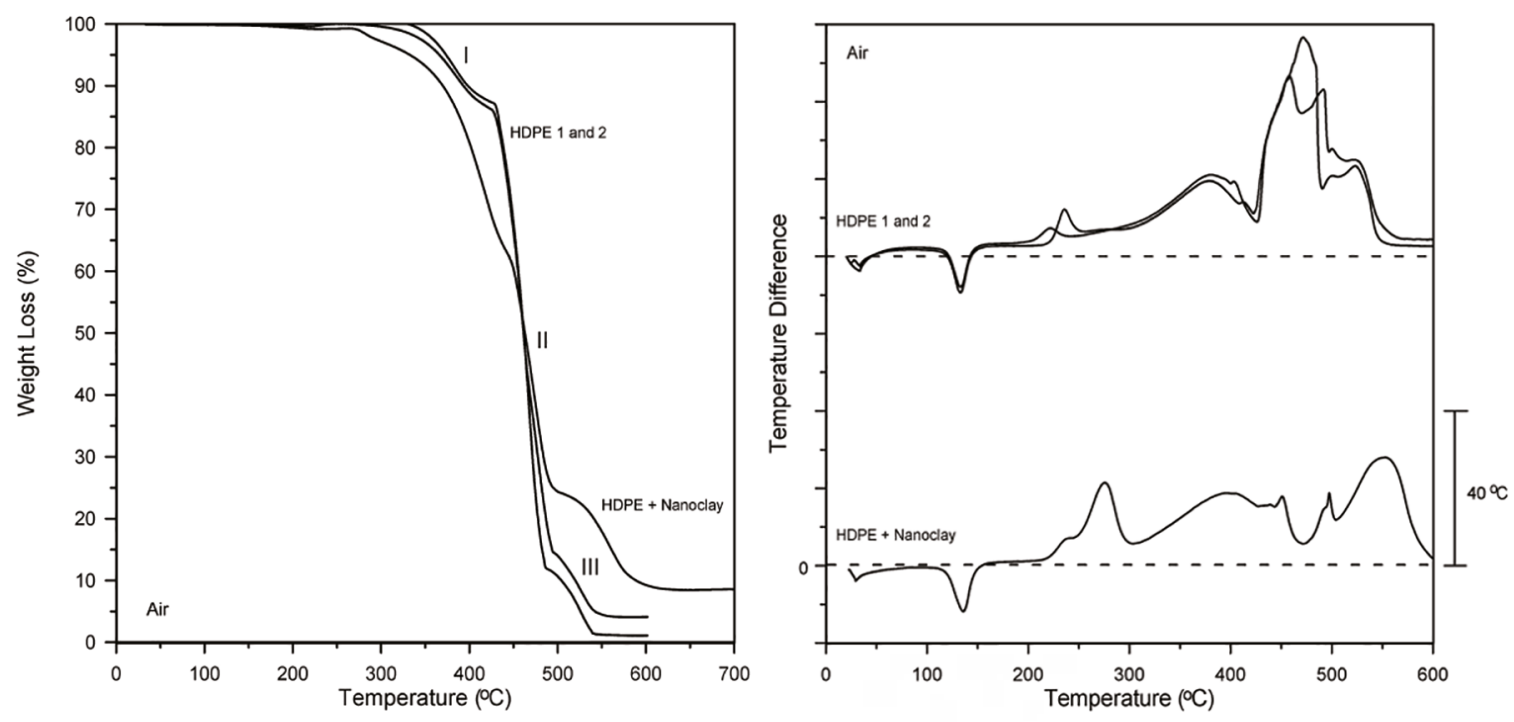

a

Figure 7. Thermal degradation in an oxidant atmosphere of the polyethylene (HDPE) and the composite polyethylene and nanoclay (HDPE + Nanoclay): a) Thermo gravimetric analysis, b) Differential thermal analysis.

The second, third and fourth events (at about 400, 470 and $500^{\circ} \mathrm{C}$ ) corresponds to the thermal oxidation of polymers of medium and large molecular weight and the combustion of the heavy compounds (char). Quite distinct behavior for the nanocomposites can be seen, especially for temperatures above $450^{\circ} \mathrm{C}$. The peaks related to the thermal oxidation of the medium and large molecular weight polymers shift and reduce indicating that a high temperature is now necessary for the oxidation of the polymers. This improvement in the thermal stability of the polymeric matrix can be explained by the fact that the nanoclay can reduce the diffusion of oxygen and the volatile degradation products acting as a mass transport barrier. 


\section{Conclusions}

This study investigated the production of polyethylene and polyethylene-clay nanocomposite using direct solvent polymerization with a Ziegler type catalyst system (TEAL and $\mathrm{TiCl}_{4}$ ). Polymers and nanocomposite samples were characterized and their thermal stability investigated. The produced polymers were multimodal high density polyethylenes composed of four molecular distributions. The crystallinity of the produced polymer was about $52 \%$. The nanocomposite presents low temperature thermal oxidation and high temperature thermal oxidation reduction. Several thermal oxidation events are noted in the polymer: oxidation of volatile compounds at $250^{\circ} \mathrm{C}$, thermal oxidation of polymers of medium and large molecular weight at 400 and $470^{\circ} \mathrm{C}$ and the combustion of the heavy compounds (char) at $500^{\circ} \mathrm{C}$. The thermal oxidation of the medium and large molecular weight polymers in the nanocomposites shift and reduces indicating an improvement in the thermal stability of the polymeric matrix due to the clay mass transport barrier effect.

\section{Acknowledgements}

This study was supported by the Conselho Nacional de Desenvolvimento Cientifico e Tecnológico (CNPq, Brazil) grant numbers 458098/2014-0 and 157196/2001-9. The Braskem PE2 is acknowledged for the GPC analysis and for provide samples of the commercial HDPE. Zênis Novais da Rocha from the Chemical Institute (UFBA) is acknowledged for their valuable help with the polymer and nanocomposite synthesis. The authors acknowledged for the thermal and XRD analysis performed at the laboratories: i) Catálise e Polímeros, ii) Energia e Ciência dos Materiais and iii) Pesquisa em Catálise e Materiais of the Federal University of Bahia.

\section{References}

1. Paul DR, Robeson LM. Polymer nanotechnology: nanocomposites. Polymer. 2008;49(15):3187-3204.

2. Camargo PHC, Satyanarayana KG, Wypych F. Nanocomposites: synthesis, structure, properties and new application opportunities. Materials Research. 2009;12(1):1-39.

3. Silva BL, Nack FC, Lepienski CM, Coelho LAF, Becker D. Influence of intercalation methods in properties of clay and carbon nanotube and high density polyethylene nanocomposites. Materials Research. 2014;17(6):1628-1636.

4. Barbosa R, Morais DDS, Nóbrega KC, Araújo EM, Mélo TJA. Influence of processing variables on the mechanical behavior of HDPE/clay nanocomposites. Materials Research. 2012;15(3):477-482.
5. Araújo EM, Barbosa R, Rodrigues AWB, Melo TJA, Ito EN. Processing and characterization of polyethylene/Brazilian clay nanocomposites. Materials Science and Engineering: A. 2007;445-446:141-147.

6. Pandey JK, Reddy KR, Kumar AP, Singh RP. An overview on the degradability of polymer nanocomposites. Polymer Degradation and Stability. 2005;88(2):234-250.

7. Jin YH, Park HJ, IM SS, Kwak SY, Kwak S. Polyethylene/clay nanocomposite by in-situ exfoliation of montmorillonite during Ziegler-Natta polymerization of ethylene. Macromolecular Rapid Communications. 2002;23(2):135-140.

8. Ramazani A, Tavakolzadeh F, Baniasadi H. In situ polymerization of polyethylene/clay nanocomposites using a novel claysupported Ziegler-Natta catalyst. Polymer Composites. 2009;30(10):1388-1393.

9. Nikkhah SJ, Ramazani A, Baniasadi H, Tavakolzadeh F. Investigation of properties of polyethylene/clay nanocomposites prepared by new in situ Ziegler-Natta catalyst. Materials and Design. 2009;30(7):2309-2315.

10. Abedi S, Abdouss M, Nekoomanesh-Haghighi M, Sharifi-Sanjani $\mathrm{N}$. PE/clay nanocomposites produced via in situ polymerization by highly active clay-supported Ziegler-Natta catalyst. Polymer Bulletin. 2013;70(4):1313-1325.

11. Haag RB, Silva JC, Abarca JRQ, Coutto Filho O, inventors. Petroleo Brasileiro - Petrobras SA, assignee. Process for preparing a Ziegler type catalytic system and process for preparing ultra high molecular weight polyethylene. US patent 4983693. 1991 Aug 08

12. American Society for Testing and Materials (ASTM). D402011 - Standard Specification for Ultra-High-MolecularWeight Polyethylene Molding and Extrusion Materials. West Conshohocken, PA: ASTM International; 2018.

13. Roxo G, Bittencourt B. UHMWPE molecular weight determination for viscosimetric analysis. São Paulo: Technical Bulletin (UTEC) - Braskem; 2006.

14. Prime RB, Bair HE, Vyazovkin S, Gallagher PK, Riga A. Thermogravimetric Analysis (TGA). In: Menczel JD, Prime $\mathrm{RB}$, editors. Thermal analysis of polymers: fundamentals and applications. London: John Wiley \& Sons; 2009.

15. American Society for Testing and Materials (ASTM). D647499 - Standard test method for determining molecular weight distribution and molecular weight averages of polyolefins by high temperature gel permeation chromatography. West Conshohocken, PA: ASTM International; 2018.

16. Khaghanikavkani E, Farid MM. Thermal pyrolysis of polyethylene: kinetic study. Energy Science and Technology. 2011;2(1):1-10.

17. Peterson JD, Vyazovkin S, Wight CA. Kinetic of the thermal and thermal-oxidative degradation of polystyrene, polyethylene and poly(propylene). Macromolecular Chemistry and Physics. 2001;202(6):775-784. 